\title{
SOBRE LA TRADUCCIÓN DE MARÍA LUISA ACUÑA DEL PROTÁGORAS DE PLATÓN
}

\author{
On the translation of Plato's Protagoras by María Luisa Acuña
}

\author{
Marcela Coria* \\ Universidad Nacional de Rosario \\ coriamarcela@hotmail.com
}

\section{Palabras clave \\ Protágoras; \\ Platón; \\ María Luisa Acuña; traducción}

\section{Resumen}

En 1974, la Prof. María Luisa Acuña (1931-2020) realizó la primera versión española hecha por una argentina del Protágoras de Platón, publicada por la Facultad de Humanidades de la Universidad Nacional del Nordeste (UNNE). La Prof. Acuña es autora no solamente de la traducción sino también de las notas al texto español y al texto griego. La obra, que constituye un verdadero aporte a los estudios clásicos en Argentina y, por extensión, a todo el ámbito de los países de lengua española, tiene sobrados méritos, lo cual se evidencia, por ejemplo, en el ritmo ágil de las primeras escenas del prólogo (que tiene un marcado estilo coloquial, casi divertido por momentos), en las elecciones léxicas de la traductora, en su profundo conocimiento del vocabulario técnico y del pensamiento de Platón y en la erudición de las notas. El objetivo de este ensayo es señalar algunos de esos méritos y transmitir, en general, mi propia experiencia de lectura de esta magnífica versión del Protágoras.

\begin{abstract}
In 1974, Prof. María Luisa Acuña (1931-2020) carried out the first Spanish version of Plato's Protagoras made by an Argentinian woman. It was published by the Facultad de Humanidades of the Universidad Nacional del Nordeste (UNNE). Prof. Acuña is the author not only of the translation but also of the notes to the Spanish as well as to the Greek texts. Her work is a valuable contribution to Classical Studies in Argentina and, more widely, to all Spanish-speaking countries, because it truly has many virtues. This can be seen, for example, in the agile rhythm of the first scenes in the prologue (which has a noticeable colloquial style, almost funny at times), in lexical choices, in the translator's deep knowledge of Plato's technical vocabulary and thought and in the erudition that the notes show. The aim of this essay is to highlight some of these virtues and, in general, to share my own reading experience of this remarkable version of Protagoras.
\end{abstract}




\section{Sobre la traducción de María Luisa Acuna del Protágoras de Platón}

Suelo pensar que la autorreferencia solamente puede escapar de la acusación de pedantería cuando constituye un punto de partida para la reflexión sobre un autor, una obra, un problema, un tema. En este ensayo, voy a recurrir a ella, pero solo como disparador de estas breves notas sobre la traducción del Protágoras de Platón de la querida María Luisa Acuña, fallecida el 5 de septiembre de 2020.

Corría el año 2006 y me preparaba, con el entusiasmo propio de una joven graduada de Letras que desde hacía un par de años se dedicaba a la docencia universitaria de la lengua griega, para dictar un seminario final de la carrera de Licenciatura en Letras con Orientación en Lenguas y Literaturas Clásicas, en la Universidad Nacional de Rosario. Varios años atrás, en un momento de epifanía que experimentamos todos los que abrazamos esta disciplina, había descubierto con alegría y cierto vértigo que quería dedicar mi vida académica a lo que en un sentido muy amplio llamamos estudios clásicos, y específicamente a la lengua y la cultura griegas. Mi maestra y formadora en la Universidad, la Prof. Lena Balzaretti (1941-2011), me lo dijo una vez claramente: hay un momento en el que uno sabe que se ha producido un vínculo con el mundo griego antiguo que no se romperá jamás. Ciertamente, un vínculo lleno de éros, de curiosidad, de expectativas, de avidez de conocimientos. Ese momento me llegó, durante la carrera, cuando cursé "Lengua Griega II” y ella dictaba las clases de trabajos prácticos.

Lena Balzaretti fue una gran traductora, y publicó varias versiones, de Aristófanes y Filón de Alejandría sobre todo, y juntas, como maestra y discípula, también de Aristófanes. Por una profunda convicción interna, ella sostenía que los profesores de griego debían traducir. La cito textualmente: "Todo profesor de griego debería dedicar sus esfuerzos a la traducción de obras que, de otra manera, nos vemos obligados a recibir pasivamente de los centros culturales donde se traduce de manera continua y renovada" (Balzaretti, 1998, p. 2). Naturalmente, la tarea de traducir textos antiguos es muy exigente y requiere profundos conocimientos no solo de la lengua origen y la lengua meta, por supuesto, sino también del autor traducido, su época, su pensamiento, su contexto cultural, histórico, filosófico, político y religioso. Pero, como sostenía Balzaretti, es una tarea esencial para transmitir a las generaciones de hablantes de lenguas distintas y muy distantes en el tiempo y en el espacio la obra de un autor que merece ser conocido y estudiado, y también, como expresó Marcelo D. Boeri en un agudo artículo, "para apresar, en la medida de lo posible, los detalles más sutiles que quedan a veces opacados incluso en las mejores traducciones” (2013, p. 170).

La Prof. María Luisa Acuña (1931-2020), muchos años antes, había realizado una verdadera proeza seguramente con la misma inspiración que subyace a estas palabras de Balzaretti: traducir el Protágoras de Platón en la ciudad de Resistencia, en la Facultad de Humanidades de la Universidad Nacional del Nordeste (UNNE). Muy lejos de Madrid, lejos de Buenos Aires: en Resistencia, provincia de Chaco. La traducción anotada y con texto griego, publicada en 1974, tiene sobrados méritos, como reconoció la misma Prof. Acuña en una comunicación a su amigo Jorge Castillo el 15 de marzo de 2020: "figura en la bibliografía platónica en francés dirigida por Juliette Ernest, porque es la primera versión castellana hecha por una argentina, en nuestro país” (párr. 5). A describir algunos de esos 
méritos quiero dedicar este breve ensayo, en el que intentaré transmitir mi propia experiencia de lectura de esta traducción del Protágoras, es decir, el modo particular, como profesora de griego, en el que me relacioné con este texto.

Corría el año 2006, decía, y quería plantear el seminario que estaba preparando para estudiantes avanzados de Letras y Filosofía más bien como un taller de traducción, y en particular de traducción de algunos pasajes filosóficamente muy significativos del Protágoras. Como se sabe, este diálogo pertenece a la época de juventud de Platón. El tema principal del diálogo es la discusión que puede expresarse en tres interrogantes: a) ¿qué es la virtud, aretê? (preocupación típicamente socrática, basada en los diferentes significados que se atribuyen al término; cfr. 360e; 361c), b) ¿hay unidad entre las virtudes, o existen varias virtudes diferentes? (pregunta por la relación entre el todo y las partes; cfr. 329c-333e; 348b-349d; 359a-d), y c) ¿es susceptible de ser enseñada la virtud?, y en caso afirmativo, ¿cuál es la mejor manera de enseñarla, es decir, el mejor tipo de paideía para la adquisición de la(s) virtud(es)? (inquietud que se relaciona con la polémica de Sócrates con los sofistas y con la oposición del filósofo a la retórica; cfr. 319a-320b; 323c-324d; 325b; 326e; 361a-c). Para intentar esclarecer estas cuestiones, Sócrates pone a prueba al famoso sofista acerca del objeto de su enseñanza, y a partir de la virtud política de la cual Protágoras se dice maestro, la discusión se centra paulatinamente en el problema de la virtud sin más. Ante la duda socrática -expresada, como es habitual, por medio de preguntas incisivas con una fuerte dosis de ironía- de si la virtud puede enseñarse o no, se encadena un diálogo con una conclusión paradójica y aporética que incluso puede resultar irritante o decepcionante para el lector moderno: la necesidad de comenzar nuevamente el diálogo partiendo desde las diferentes posiciones que parecen haber adoptado, hacia el final, los dos interlocutores. Este final aporético pone en primer plano la importancia de la forma dialógica, del método dialéctico empleado por Platón en su escritura filosófica. El diálogo es comunicación, conversación, discusión, intercambio vivo en el que no hay dogmas teóricos ni axiomas dados de una vez y para siempre, sino en el que el conocimiento se construye dialécticamente.

La mayor parte de los estudiosos de Platón coinciden en señalar que este diálogo es uno de los más bellos del filósofo: su movimiento, su vivacidad, la maestría en la caracterización de los personajes y en el manejo del léxico y de la sutileza, la ironía contenida no solo en palabras aisladas sino también en frases enteras. Todos estos elementos configuran el estilo particular de este diálogo y fundamentan esta opinión compartida por los críticos más perspicaces de la escritura filosófica de Platón. En la prosa platónica, y en especial en el Protágoras, el estilo alcanza un vuelo poético acorde con la sólida cultura artística del autor. Pero también resulta evidente a cada momento, mientras conversan los protagonistas, prestigiosos hombres de la Atenas de la época, la presencia del lenguaje vivo, de la respuesta coloquial, de la frase en la cual los numerosos componentes elididos se reconocen solamente en el contexto de esa mímesis dialógica que propone el filósofo. De allí el interés estético, literario, que reviste dentro de la producción platónica, y de allí también que el Protágoras mereciera, a mi juicio en ese momento, un estudio riguroso de los problemas filosóficos que plantea y de la forma en que se transmiten esos problemas, es decir, de las palabras, las estructuras y el estilo, mediante el análisis filológico. Resulta sumamente obvio señalar que la lectura de un texto en su lengua original permite no solo una comprensión mucho más acabada y profunda de los conceptos y los cuestionamientos principales del texto sino incluso un mayor acercamiento, por más sutil que sea, a la cosmovisión 
que subyace y contiene intrínsecamente una lengua determinada. Por eso me proponía abordar los conceptos más importantes, las estructuras sintácticas predominantes, el movimiento interno del diálogo y algunas particularidades de la prosa platónica: para que los estudiantes lograran tanto esa comprensión como ese acercamiento.

Cuando recién estaba tomando forma en mí la idea de dedicar el seminario a este diálogo, la única traducción al español que tenía a mano, excelente traducción, por cierto, era la de Carlos García Gual publicada en 1985 en la editorial Gredos, en ese centro cultural donde se traduce de manera continua, Madrid. Para poder contar con otras traducciones y encarar concretamente la preparación del programa y la bibliografía para los estudiantes, le pregunté a la Prof. Balzaretti si tenía alguna otra. Entonces, inmediatamente fue a su biblioteca y me regaló su ejemplar del Protágoras: la traducción realizada por María Luisa Acuña en Resistencia, sobre la base del texto establecido por Alfred Croiset con la colaboración de Louis Bodin en la colección Les Belles Lettres. ${ }^{1}$ Naturalmente, el ejemplar evidenciaba los rastros físicos del paso del tiempo (un tono amarillento, ciertas hojas sueltas) y de varias lecturas, hechas por ella y por su esposo, otro gran profesor, no de lenguas clásicas sino de Filosofía, Guillermo Porrini.

Recuerdo que verdaderamente disfruté (en el sentido etimológico de la palabra) mucho la primera lectura de la traducción: la prosa tenía un ritmo fluido y ágil, era muy amena, había en ella un uso preciso de los términos filosóficos técnicos y un léxico cuyas resonancias me eran más familiares que las del léxico del español europeo (por ejemplo en el empleo de las formas pronominales y verbales de segunda persona plural, o en la traducción de $\pi \alpha i ̃$ por "chico" en 310a) y tenía notas tanto al texto español como al texto griego muy pertinentes, claras y útiles para la comprensión de cuestiones de diversa índole (las notas a la traducción española, 40 en total, incluyen explicaciones de algunas expresiones o términos, datos acerca de los personajes de la época y de los dioses mencionados en el diálogo, referencias a obras poéticas citadas por el filósofo, etc.; a las notas al texto griego me referiré más adelante). Además, el hecho de ser una edición bilingüe (realizada en tiempos en los que no era habitual que las imprentas argentinas contaran con fuentes griegas) resultaba muy práctico para los estudiantes; me decidí entonces a tomarla como base para el seminario.

Entre los muchos méritos de esta traducción, como señalaba, está el ritmo ágil de la prosa. Esto es especialmente notable en el prólogo (309a-314b), por ejemplo, en el diálogo entre Sócrates y el Amigo. Como suele suceder también en otros diálogos platónicos, este prólogo tiene un estilo coloquial, casi divertido por momentos, en el que se pone de manifiesto la complicidad que existe entre los interlocutores. Ambos se han encontrado por casualidad, y de la chanza del Amigo a Sócrates

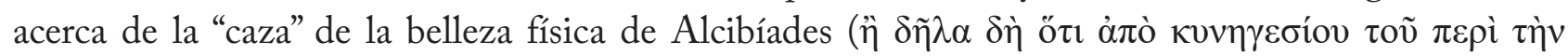

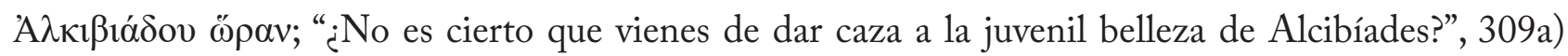
pasan a conversar sobre la belleza -intelectual, more socratico- del abderitano Protágoras (309c), que está en la ciudad, según informa Sócrates al Amigo (309d). El texto griego de estas primeras líneas, como corresponde al ritmo de un diálogo casual y coloquial, abunda en partículas y braquilogías. El

1. Ver: Platón, Oeuvres complètes (1963). 
mismo efecto comunicativo produce la traducción de Acuña, lo cual tiene una influencia decisiva en la impresión que causa la versión en español al lector hispanoparlante: no se está hablando seriamente aquí. La traductora cumple sobradamente lo que, muchos años después, propondrá Edith Grossman:

los traductores necesitamos desarrollar un agudo sentido del estilo en ambos idiomas, afilando y ampliando nuestra conciencia crítica del impacto emocional de las palabras, el aura social que las rodea, el escenario y el clima que las informan, la atmósfera que crean. (2011, p. 18)

Este prólogo, además, abunda en deliciosas anécdotas: la visita de Hipócrates a Sócrates a la madrugada para anunciarle la llegada de Protágoras a Atenas (310a-311a), la conversación entre ambos primero en el patio de la casa de Sócrates y luego en el camino hacia la casa de Calias, donde se hospedaba el sofista (311a-341c), y la renuencia del esclavo a abrirles la puerta (314c-e). También es deliciosa la traducción que de ellas realiza Acuña, y lo logra mediante un ritmo dinámico y expresiones vigorosas que permiten apreciar, incluso para quien desconoce el griego, la vivacidad de las escenas, los personajes y los diálogos.

En este mismo prólogo, cuando Sócrates expresa su desconfianza con respecto a las enseñanzas de Protágoras (313d), hay una elección léxica muy acertada: el verbo "traficar", que tiene un sentido muy específico en nuestra variante regional del español, para la traducción del participio sustantivado $\pi \varepsilon \rho$ ó́ $\gamma \circ \tau \tau \varepsilon \varsigma$, en consonancia con el participio también sustantivado $\kappa \alpha \pi \eta \lambda \varepsilon v ́ o v \tau \varepsilon \varsigma$, que aparece poco después en el mismo pasaje. Porque propiamente, el verbo "traficar" es $\kappa \alpha \pi \eta \lambda \varepsilon v ́ \varepsilon ı v$, no $\pi \varepsilon \rho i \alpha ́ \gamma \varepsilon ı v$,

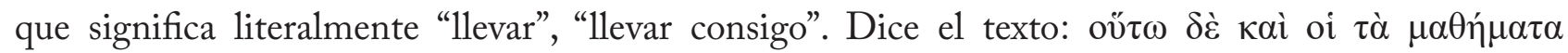

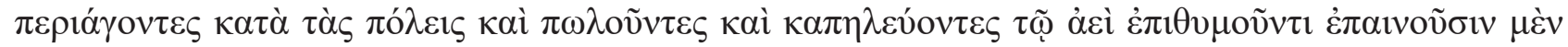

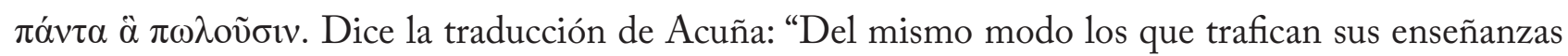
por las ciudades, tanto vendedores como traficantes, alaban siempre al cliente todo lo que venden”. La traducción evidencia un conocimiento preciso por parte de Acuña de la postura de Sócrates en este diálogo con respecto a los sofistas: estos no "llevan" o "llevan consigo" simplemente las enseñanzas ( $\tau$ ̀̀ $\mu \alpha \theta \eta \dot{\eta} \mu \alpha \alpha)$ que difunden por dinero, ${ }^{2}$ lo que indicaría una visión más bien neutra de su tarea, sino que, para Sócrates, esta tarea es análoga a la de los que comercian al por menor, en pequeña escala, lo cual está lejos de mostrar una visión neutra. Acuña lo entiende y por eso traduce con el mismo lexema tanto $\pi \varepsilon \rho$ ló $\gamma o v \tau \varepsilon \varsigma$ como $\kappa \alpha \pi \eta \lambda \varepsilon v ́ o v \tau \varepsilon \varsigma$. García Gual traduce así el mismo pasaje: "Así también, los que introducen sus enseñanzas por las ciudades para venderlas al por mayor o al por menor a quien lo desee, elogian todo lo que venden”. Por supuesto, la traducción es correcta, pero, en cuanto a $\pi \varepsilon p i a ́ \gamma \varepsilon ı v$, "introducir", ciertamente, no tiene la misma fuerza que "traficar", que es más acorde con todo el contexto y con la posición de Sócrates en cuanto a los sofistas. Y menciono el contexto porque se reitera varias veces aquí la comparación entre los sofistas y los comerciantes, con dos apariciones del

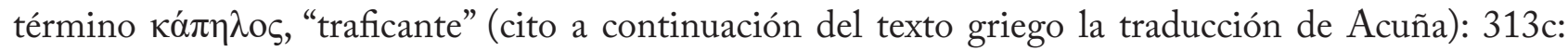

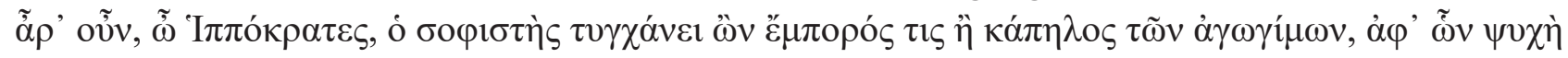
$\tau \rho \varepsilon ́ \varphi \varepsilon \tau \alpha 1 ;$ "Hipócrates, ¿el sofista es por casualidad un comerciante o traficante de los artículos con

2. Esta cuestión es reiterada en la obra: lo demuestran las frecuentes referencias a ả $\rho \gamma v ́ \rho ı v ~(310 d, 311 c, 357 \mathrm{e}), \chi \rho \eta ́ \mu \alpha \tau \alpha$ (311d y e) y $\mu 1 \sigma \theta o ́ \varsigma ~(328 b, 349 a)$. 


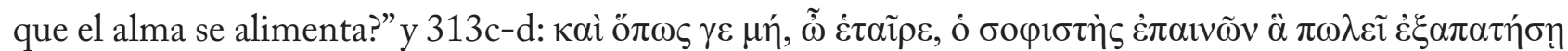

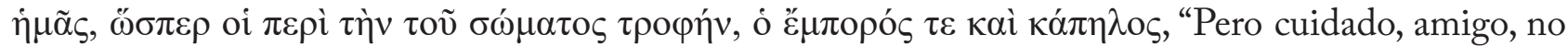
sea que alabando lo que vende, el sofista nos engañe como el comerciante y el traficante que venden el alimento del cuerpo". Comparemos las traducciones de García Gual de los mismos pasajes: 313c: "Hipócrates, ¿el sofista viene a ser un traficante o un tendero de las mercancías de que se nutre el alma?" y 313c-d: "De modo que, amigo, cuidemos de que no nos engañe el sofista con sus elogios de lo

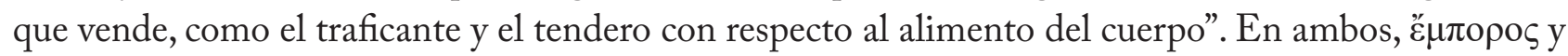

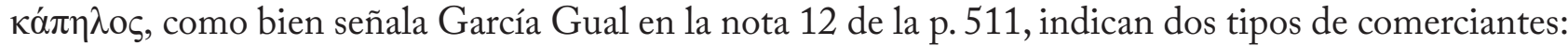
el que vende al por mayor el primero y al por menor el segundo. Pero a diferencia de Acuña, García

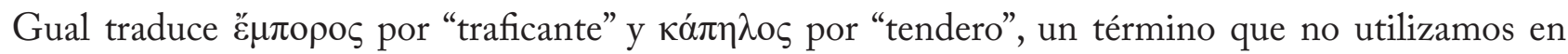
nuestra variante del español y que además es menos preciso que "traficante" para кá $\rceil \lambda$ os.

Otra elección léxica muy acertada, y muy cercana a nuestra lengua cotidiana, es la traducción

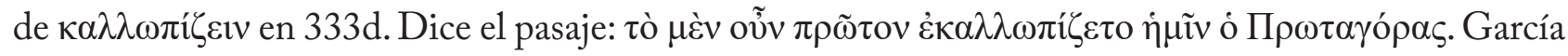
Gual traduce: "Al principio, Protágoras nos ponía reparos". Pero mucho mejor y más ajustadamente traduce Acuña: "Protágoras al comienzo se pavoneó ante nosotros". El diccionario Liddell-ScottJones (s. v.) avala esta traducción: en la acepción 3 de este verbo en voz media, dice: "to be coy or mock-modest", y cita este mismo pasaje. En efecto, eso es lo que significa este verbo en voz media: "vanagloriarse”, “jactarse”, "pavonearse”. Y esta es también la actitud de Protágoras en el diálogo; otra vez, Acuña interpreta bien. Evoco aquí las palabras de Barbara Cassin:

Es muy interesante que haya diversas maneras de traducir y diversas maneras de hacer oír una lengua en otra. Esto implica que una lengua no es simplemente un medio para comunicarse: es también una cultura, un mundo de frases, de ritmos que difieren. (2014, p. 31)

Ya hemos mencionado el ritmo ágil del prólogo; lo que vemos en este pasaje es una comprensión honda de los personajes del diálogo, de sus características, de sus disputas, del mundo de frases que construyen y de la cultura griega de la época en general.

Otro destacado mérito de esta edición son las notas al texto griego, 28 en total. Si bien se trata de notas breves, y no de las (no siempre justificadamente) abultadas notas que solemos ver en traducciones más actuales, la vocación docente de María Luisa Acuña aparece aquí en todo su esplendor. Hay notas que explican cuestiones morfológicas y/o sintácticas, otras en las que el énfasis está en los matices semánticos de los términos griegos del texto de Platón, otras en las que se pone el foco en los conceptos que apuntan al núcleo del problema filosófico planteado en este diálogo (como

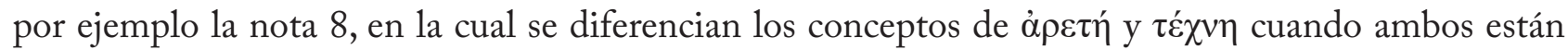
complementados por el adjetivo $\pi \mathrm{o} \lambda \iota \tau \iota \kappa \eta ́)$, otras en las que Acuña incorpora definiciones de léxicos y diccionarios (en la 9, el Lexique de Platon; en la 12, el diccionario griego de Bailly; en la 14, el de Liddell-Scott, por ejemplo), otras de contenido filosófico, y finalmente otras que explican referencias a elementos de la cultura griega que podrían ser desconocidos para un lector moderno (como la 16, en la

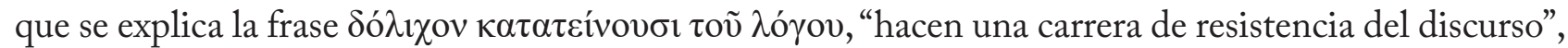
en 329 a, o la 20, en la que se alude a la práctica del sacrificio). En todas estas notas, se evidencia el profundo conocimiento de la profesora Acuña no solamente de la lengua griega sino también del pensamiento de Platón. 
Este conocimiento del pensamiento de Platón también se demuestra en la destreza de Acuña en el manejo del vocabulario técnico del filósofo. En el marco del diálogo entre Sócrates y Protágoras acerca de la posible unidad de las virtudes, el sofista ha sostenido que la ả

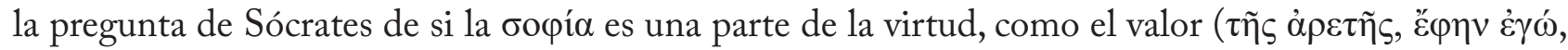

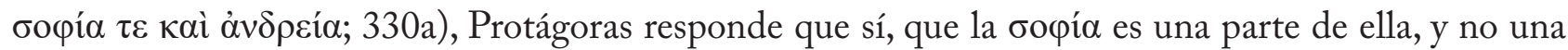

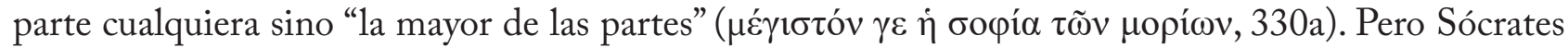
insiste, y en 330b dice: "Así que ninguna parte de la virtud es como la ciencia". En el texto griego,

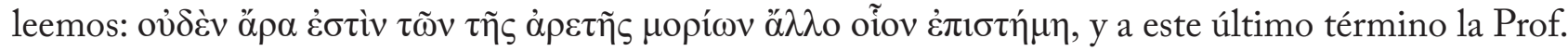

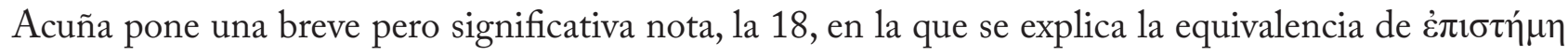
y бopía en su sentido de "ciencia práctica en el lenguaje socrático". La nota es esclarecedora porque

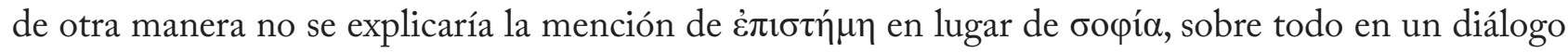

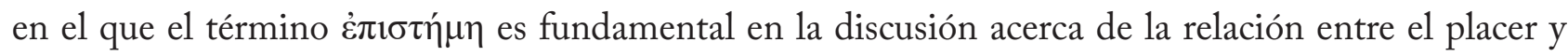
el bien, por un lado, y el dolor y el mal por otro, discusión que conduce al análisis de por qué alguien, sabiendo que algo es malo, igualmente lo hace de manera voluntaria, que ocupa una parte importante del diálogo (351b-358e) y que tendrá importantes resonancias en la filosofía posterior debido a que aquí se plantean las bases del intelectualismo socrático. A este mismo espíritu responde, a mi juicio, la

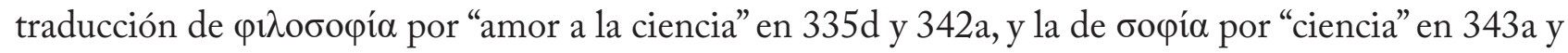

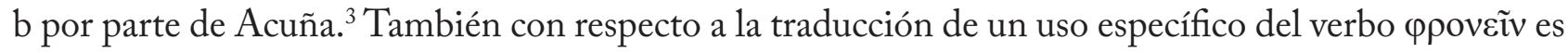

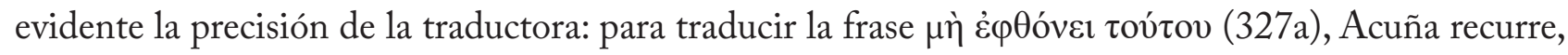
como explica en la nota 12 al texto griego, al Lexique de Platon y al diccionario Bailly para escoger la expresión "al que se rehúsa por maldad a aprender" (por el contexto se entiende que es el arte de tocar la flauta). Pero, además, en la nota 24 a la traducción española, justifica su opción:

traduzco 'rehúsa por maldad aprender' (el arte de flautista), porque me parece más ajustado que la versión: 'que a nadie le fuese negado aprender' (Bergúa). Platón no dice que se niegue el aprender a nadie, sino que nadie puede ni debe rehusarse a aprender. Recordar la conclusión del razonamiento de Protágoras en 325 a y b. (1974, p. 49)

En efecto, se nota aquí una precisa comprensión, como mencionaba antes, del pensamiento del filósofo.

Para finalizar, quisiera citar nuevamente a Barbara Cassin (2019, p. 18): "las operaciones de cultura y pensamiento son operaciones de lenguas, generalmente convertidas en textos" y, por lo tanto, "privarnos de la posibilidad de comprender y sentir esto desde adentro es privarnos de toda la sucesión, de todas las derivaciones, de todas las bifurcaciones y conexiones, privarnos de todo”. Por eso hay que estudiar griego. Por eso los profesores de griego tienen que dedicar sus esfuerzos a traducir. Así lo hizo María Luisa Acuña, durante una vida dedicada a la docencia y a la investigación. A pesar del tiempo transcurrido desde la publicación de esta traducción, ciertamente esta no ha perdido vigencia y constituye todavía hoy un magnífico aporte a los estudios clásicos en Argentina y, por extensión,

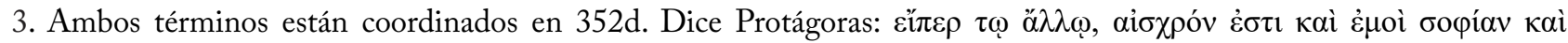

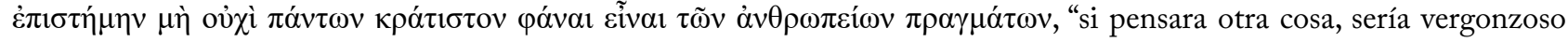
para mí, si no reconocería que la sabiduría y la ciencia son lo más poderoso de todas las cosas humanas”. 
a todo el ámbito de los países de lengua española. Por su valor intrínseco y porque fue "la primera versión castellana hecha por una argentina”, y “en nuestro país”. Espero haber mostrado en las líneas precedentes cuánta erudición y cuánto amor a la lengua y la cultura griegas subyacen a esta edición tan preciada para docentes y estudiantes de griego. Muchas gracias, María Luisa.

\section{Referencias bibliográficas}

Balzaretti, L. (1998). La importancia de estudiar griego. Hacer arte, 0 (2), 2.

Boeri, M. D. (2013). “El bien es aquello a lo que todas las cosas tienden”. Observaciones críticas a una traducción reciente de la Ética a Nicómaco de Aristóteles. Diánoia, LVIII (70), 169-189.

Cassin, B. (2014). Más de una lengua (V.Waksman, trad.). Buenos Aires, Fondo de Cultura Económica.

Cassin, B. (2019). Elogio de la traducción. Complicar el universal (I. Agoff, trad.). Buenos Aires, El cuenco de plata.

Castillo, J. (14 de septiembre de 2020). Despedida a la profesora María Luisa Acuña. Diario Norte. https://bit.ly/3ziYvml.

Grossman, E. (2011). Por qué la traducción importa (E. Gandolfo, trad.). Madrid, Katz.

Platón (1963). Oeuvres complètes. Paris, Les Belles Lettres.

Platón (1974). Protágoras (M. L. Acuña, trad.). Resistencia, Facultad de Humanidades, Universidad Nacional del Nordeste.

Platón (1985). Diálogos I (C. García Gual, trad.). Madrid, Gredos.

*Marcela Coria es Licenciada en Letras y Doctora en Humanidades y Artes con mención Filosofía, egresada de la Facultad de Humanidades y Artes de la Universidad Nacional de Rosario. En la misma Facultad es docente en las cátedras Lengua Griega I y Lengua Griega II. Ha publicado traducciones al español del griego antiguo, capítulos de libros en publicaciones conjuntas y diversos estudios en revistas especializadas y de divulgación.

RECIBIDO: 03/05/2021

ACEPTADO: 07/06/2021 